\title{
Review Article: \\ Effect of oral hypoglycaemic agents on bone metabolism in patients with type 2 diabetes mellitus
}

\author{
B. Siddhartha Kumar, ${ }^{1}$ A. Ravi Sankar, ${ }^{1}$ Alok Sachan, ${ }^{2}$ D. Prabath Kumar, ${ }^{1}$ \\ D.T. Katyarmal, ${ }^{1}$ K.V.S. Sarma ${ }^{3}$ \\ Departments of ${ }^{1}$ Medicine, ${ }^{2}$ Endocrinology, Sri Venkateswara Institute of Medical Sciences, Tirupati \\ and Department of ${ }^{3}$ Statistics Sri Venkateswara University, Tirupati
}

\begin{abstract}
Diabetes mellitus (DM) and osteoporosis are the two important public health problems in India. The burden of both these conditions is expected to increase in the near future in view of changing lifestyle habits and ageing population. Indians are at risk of osteoporosis due to their low body mass index (BMI), genetic predisposition and nutritional factors. The diseases type $1 \mathrm{DM}$ and type $2 \mathrm{DM}$ (T2DM) are associated with increased fracture risk in the disease population, in spite of difference in the bone mineral density (BMD). An increase in fracture risk is also reported among older patients with T2DM despite frequently reported normal or increased BMD. Administration of insulin stimulates osteoblast activity and bone mineral apposition rates. The impact of endogenous insulin production, insulin sensitivity, and exogenous insulin administration as an anabolic agent for bone in T2DM has not been clarified. Biguanides and sulphonylureas do not appear to have adverse effects on BMD. Preclinical evidence suggests that incretin-based drugs may be beneficial for bone, but clinical evidence to support this hypothesis is not yet available. Thiazolidinedione (TZD) group of agents have been implicated in causing osteoporosis in various animal studies and some human studies available till date. The debate regarding this is issue is still ongoing. Randomized controlled studies with larger sample size preferably involving multiple centres, multiple ethnicities are required to answer these queries.
\end{abstract}

Key words: Oral hypoglycaemic agents, Bone metabolism in bones, Type 2 diabetes mellitus

Siddhartha Kumar B, Ravi Sankar A, Sachan A, Prabath Kumar D, Katyarmal DT, Sarma KVS. Effect of oral hypoglycaemic agents on bone metabolism in patients with type 2 diabetes mellitus. J Clin Sci Res 2012;1:83-93.

INTRODUCTION

Indians in general are susceptible to obesity and metabolic syndrome. This makes diabetes mellitus (DM) a major health problem in our country. According to Diabetes Atlas 2011 published by International Diabetes Federation there are about 61 million people with DM in India. ${ }^{1}$ Various macrovascular and microvascular complications associated with DM are well known. These complications contribute to significant morbidity and mortality in patients with DM. The role of osteoporosis in contributing to the morbidity and mortality is often under stressed. As a result we do not have sufficient data regarding the prevalence of osteoporosis among patients with DM. Another reason for not suspecting osteoporosis among patients with DM is the false notion that type 2 diabetes mellitus (T2DM) are protected against osteoporosis. Various factors such as decreased mobility due to obesity, use of oral hypoglycaemic agents make patients with DM

Received: 24 March, 2012.

Corresponding Author : Dr B. Siddhartha Kumar, Chief, Division of Rheumatology, Professor, Department of Medicine Sri Venkateswara Institute of Medical Sciences, 517507, India. e-mail: siddartha59@gmail.com peripheral neuropathy, decreased vision, frequent hypoglycaemic episodes and frequent visits to the slippery bathrooms due to polyuria increases the risk of falls in patients with DM. This increased risk of falls plus the associated osteoporosis makes fractures more common in patients with DM. Among the various factors that increase the risk of fractures in patients with DM, usage of oral hypoglycaemic agents is one factor which is iatrogenic.

These factors put together makes it important to see that osteoporosis is prevented in patients with DM by early initiation of measures to preventive measures.

\section{OSTEOPOROSIS}

Osteoporosis is a disease characterized by reduction in the bone mass and disruption of bone architecture leading to impaired skeletal strength and an increased susceptibility of fractures. ${ }^{2}$

Osteoporosis is one of the major public health problems, especially in the elderly causing 
considerable socio-economic burden. ${ }^{3}$ With the increasing proportion of the elderly population all over the world, this problem needs special attention. By increasing the risk of fracture the proportion of dependant among the elderly increases and this in turn causes a great burden on health care system. ${ }^{4}$ Nearly $50 \%$ of the world population resides in Asia and significant numbers of Asian population are living in South-East Asia. The phenomenon of increase in the elderly population will place enormous burden on the health care system in the South-East Asia. ${ }^{5}$

The estimated lifetime risk of osteoporotic fracture is as high as $50 \%$ in Asian women. Osteoporotic fractures occur one to two decades earlier in the Asian women when compared to their western counterparts. The factors which influence the risk of osteoporosis in the later life includes predominantly peak bone density along with other factors such as genetic factors, ethnicity, race, environment, lifestyle. ${ }^{6-10}$ The factors such as nutrition, body weight, ${ }^{11,12}$ exposure to sex hormones at puberty ${ }^{13,14}$ and level of physical activity ${ }^{15}$ are not only important for the acquisition of maximal bone mass but also for its maintenance throughout life..$^{16,17}$

The important underlying mechanism in all cases of osteoporosis is an imbalance between process of bone resorption and bone formation. Up to $10 \%$ of the total bone is actively involved in the process of remodelling at any point of time and this process takes place in the bone multicellular units. The process of bone remodelling is first described by Frost. ${ }^{18}$

Bone is resorbed by osteoclast cells (derived from the bone marrow), after which new bone is deposited by osteoblast cells. The three main mechanisms by which osteoporosis develop are inadequate peak bone mass, excessive bone resorption and inadequate formation of new bone during remodelling. Interplay of these three mechanisms underlies the development of fragile bone tissue. ${ }^{19}$

Hormonal factors strongly determine the rate of bone resorption. Lack of oestrogen (e.g., as a result of menopause) increases bone resorption as well as decreasing the deposition of new bone that normally takes place in weight-bearing bones. The amount of oestrogen needed to suppress this process is lower than that normally needed to stimulate the uterus and breast gland. The á-form of the oestrogen receptor appears to be the most important in regulating bone turnover. ${ }^{19}$ In addition to oestrogen, calcium metabolism plays a significant role in bone turnover, and deficiency of calcium and vitamin D leads to impaired bone deposition; in addition, the parathyroid glands react to low calcium levels by secreting parathyroid hormone (PTH), which increases bone resorption to ensure sufficient calcium in the blood.

Various molecular signals like receptor activator for nuclear factor êâ ligand (RANKL) regulate the activation of the osteoclast. This molecule is produced by osteoblasts and other cells (e.g. lymphocytes). RANKL stimulates receptor activator of nuclear factor êâ (RANK). Osteoprotegerin (OPG) binds RANKL before it has an opportunity to bind to RANK, and hence suppresses its ability to increase bone resorption. RANKL, RANK and OPG are related to tumour necrosis factor (TNF) and its receptors in their chemical structure. The role of the wnt signalling pathway is recognized but less well understood. Local production of eicosanoids and interleukins plays role in regulation of bone turnover, and excess or reduced production of these mediators may lead to the development of osteoporosis. ${ }^{19}$ Trabecular bone is more active because of the inhabitation of the osteoblasts and osteoclasts near the bone surface. Trabecular bone is more subject to bone turnover and to remodelling. Both the bone density and bone microarchitecture are disrupted. The weaker spicules of trabecular bone break lead to formation of "microcracks" and are replaced by weaker bone. Common osteoporotic fracture sites, the wrist, the hip and the spine, have a relatively high trabecular bone to cortical bone ratio.

\section{Risk factors}

Risk factors for osteoporotic fracture can be nonmodifiable and potentially modifiable. 


\section{Non-modifiable risk factors}

The most important risk factors for osteoporosis are advanced age (in both men and women) and female sex; oestrogen deficiency following menopause is correlated with a rapid reduction in bone mineral density (BMD), while in men a decrease in testosterone levels has a comparable (but less pronounced) effect. European or Asian ancestry predisposes for osteoporosis, although it occurs in all ethnic groups. ${ }^{20}$ Family history increases the risk of fracture; the heritability of the fracture as well as low BMD is relatively high, ranging from $25 \%$ to $80 \%$. At least 30 genes are associated with the development of osteoporosis. ${ }^{19}$ Those who have already had a fracture are prone for osteoporotic fracture twice more commonly then people of the same age and sex. ${ }^{21}$

\section{Potentially modifiable risk factors}

Excess alcohol: chronic heavy drinking [alcohol intake greater than 3 units/day (a unit is defined as $14 \mathrm{~g}$ of alcohol)] especially at younger age increases risk of osteoporotic fracture significantly, ${ }^{22}$ whereas, small amounts of alcohol do not increase osteoporosis risk and may even be beneficial. ${ }^{23}$

Tobacco smoking : Tobacco smoking inhibits the activity of osteoblasts and is an independent risk factor for osteoporosis. Smoking results in lower body weight, increased breakdown of exogenous oestrogen and earlier menopause, this can contribute to lower BMD. ${ }^{24}$

Vitamin D deficiency: Vitamin D deficiency has also emerged as a potentially modifiable risk factor for osteoporotic fractures. ${ }^{25}$

Malnutrition: Low dietary calcium and/or phosphorus, magnesium, zinc, boron, iron, fluoride, copper, vitamins A, K, E and C (in addition to vitamin $\mathrm{D}$ ). Excess sodium along with acidosis are known to inhibit bone formation. ${ }^{26}$

Physical activity: Bone remodelling occurs in response to physical stress, and weight bearing. Exercise can increase peak bone mass achieved in adolescence. In adults, physical activity helps maintain bone mass and physical inactivity can lead to significant bone loss. ${ }^{24}$ Incidence of osteoporosis is lower in overweight people. ${ }^{27}$
Hormonal status: Oestrogen deficiency is known to cause osteoporosis. Even though oestrogen therapy can prevent osteoporosis, its use is advisable in patients with other compelling indications for hormonal replacement. Pregnancy is associated with bone losses of approximately $3 \%$ to $5 \%$ at the spine and hip in some studies, ${ }^{28-}$ ${ }^{30}$ while other studies have found that bone density remains stable during this period of increased calcium demand ${ }^{31}$ or declines significantly only at the trochanter. ${ }^{32}$

In contrast, lactation has more consistent and profound effects on bone density. Bone loss of $3 \%$ to $10 \%$ at the spine and hip are seen over three to six months of lactation. ${ }^{33}$ Bone loss is related to duration of lactation and duration of amenorrhoea and calcium supplementation has not shown to prevent this bone loss. ${ }^{34-36}$

PTH-related protein, which is secreted by the lactating mammary gland, plays a role in the control of calcium mobilization during lactation. ${ }^{37,} 38$ Circulating calcitonin ${ }^{39}$ and the oestrogen deficiency that is characteristic of lactation may also be involved in the control of bone loss during this time.

Bone loss reverses during and after weaning, but the regulators mediating bone recovery in this setting have not been clearly defined. ${ }^{40}$ Recovery from lactation-associated bone loss may continue for 18 months or longer and studies in both humans and animal models suggest that the pattern and extent of bone recovery may be site specific with complete reversal at the spine and incomplete or slower recovery at other sites. ${ }^{41,42}$ Most studies have not found an association between either parity or lactation and osteoporosis or increased fracture risk in postmenopausal women. ${ }^{43,44}$

\section{Secondary osteoporosis}

Medical conditions or treatments ${ }^{45}$ that interfere with the attainment of peak bone mass and may cause secondary osteoporosis are listed in the Table 1. During secondary osteoporosis, an increased rate of bone remodelling or an increase in the quantity of bone being remodelled causes an overall increase in the rate of bone loss. Osteoporosis can also be the result of disorders 
where bone marrow cavity expands at the expense of trabecular bone leading to decreased strength of the bone.

\section{Diagnosis of osteoporosis}

The measurement of BMD by dual-energy x-ray absorptiometry (DEXA) as an index of bone strength and fracture risk, has been used in postmenopausal women predominantly. The distribution of BMD follows a Gaussian distribution in young healthy adults until the peak bone mass is reached. The BMD values in the individuals can be expressed as standard deviation (SD) units in relation to the reference population. This help in reduction of difficulties associated with differences in calibration between various instruments. When the SD units are used in relation to the young healthy adult population, the measurement is referred to as T-score. When the SD units are used in relation to the age-matched norms, the measurement is referred to as Zscore. ${ }^{46,47}$

The T-score is calculated using the following formula: ${ }^{46,47}$

T-score $=($ observed BMD - young normal mean) / standard deviation of young normal mean

In postmenopausal women, normal bone has been defined as BMD greater than 1 SD below the young adult female reference mean (T-score $\mathrm{e} \geq$ $-1 \mathrm{SD})$. Osteopenia has been defined as BMD greater than $1 \mathrm{SD}$ below the young adult female mean, but less than 2.5 SD below this value (Tscore $<-1$ and $>-2.5 \mathrm{SD})$. Osteoporosis has been defined as BMD 2.5 SD or more below the young adult female mean (T-score $\leq-2.5 \mathrm{SD}$ ) with or without the presence of a fragility fracture according to World Health Organization (WHO) ${ }^{47}$ In premenopausal women, the population with fracture is much lower when compared with postmenopausal women, and the relationship between BMD and fracture risk is not the same. Therefore, the diagnostic guidelines and the treatment practices based on bone density measurements in postmenopausal women can apply to this population. The International Society for Clinical Densitometry (ISCD) recommends use of BMD Z-scores at the lumbar spine, total hip, femoral neck, and distal radius, rather than Tscores in premenopausal women and men less than 50 years age. ${ }^{47,48}$ The BMD assessment in the Tscores can be applied to the men aged more than 50 years. ${ }^{47-49}$ International Osteoporosis Foundation and WHO recommends the National Health and Nutrition Examination Survey (NHANES) reference database from women belonging to the age group 20-29 years as the reference range. ${ }^{46}$

In women, bone loss occurs predominantly after the menopause. In the young healthy population, $15 \%$ of women have a T-score of less than -1 and thus have low bone mass or osteopenia. ${ }^{46}$ Because of the normal distribution for BMD, about $0.5 \%$ of women fall into the osteoporotic range,

Table 1: Various conditions leading to secondary osteoporosis

Chronic kidney disease

Cushing's disease

Hepatic dysfunction

Anorexia nervosa and bulimia

Rheumatoid arthritis

Malabsorption syndromes (e.g., coeliac disease, tropical sprue, blind loop syndromes)

Multiple sclerosis

Chronic obstructive pulmonary disease

Scurvy

Endocrinological diseases (hyperparathyroidism, hyperthyroidism, hypercortisolism)

Haematological diseases (thalassemia, multiple myeloma, leukaemia)

Metastatic bone diseases

Medications or chemicals (cigarette smoking, corticosteroid therapy, alcohol abuse, lithium, aluminium, barbiturates, antacids containing aluminium etc.,)

Source: reference 45 
with a $\mathrm{T}$ score of -2.5 or less. Furthermore, the proportion of women osteoporosis at any one anatomical site increases greatly with age in much the same way as fracture risk increases with age. ${ }^{46}$ The ISCD recommends avoidance of the term osteopenia. Instead, the term "below the expected range for age" has been considered appropriate when Z-scores $<-2.0 \mathrm{SD}$ are observed. ${ }^{48,49}$

A young woman with low BMD for age and with risk factors for fracture or secondary causes of osteoporosis (such as glucocorticoid therapy, hypogonadism, or hyperparathyroidism) may be defined as having premenopausal osteoporosis in addition to the BMD score criteria obtained by DEXA as described above.

\section{Fragility fracture}

Despite this dichotomy, new bone formation as well as bone micro-architectural integrity is altered in the diabetic state, leading to an increased risk for fragility fracture and inadequate bone regeneration following injury.T2DM was associated with $2 \%$ - $8 \%$ higher regional and whole body BMD (both areal and volumetric measures) even with adjustment for body composition variables of lean mass, fat mass, and abdominal visceral fat and other confounding factors in a study. ${ }^{50}$ The unique finding of lower spine bone volume was observed in this study. Another study ${ }^{51}$ demonstrated that at lower bone volumes the structural integrity of cancellous bone is rapidly compromised. Lower spinal bone volumes in patients with T2DM can account for increased incidence of fractures in these patients.

The aetiology of the increased BMD in T2DM remains unclear, as evidence of decreased bone formation, increased bone resorption and increased bone formation have all been reported in studies on subjects with T2DM. ${ }^{52-54}$ These studies frequently do not specify and/or analyze results on the basis of treatment type (diet vs. oral hypoglycaemic agent Vs. insulin), which could also account for the inconsistencies in studies of bone density in T2DM. Animal studies illustrate these differences. Specifically, in mice, rosiglitazone administration was observed to have significant decrease in BMD, bone volume, and bone formation rate associated with a decrease in osteoblast specific gene expression, ${ }^{56}$ and increased apoptotic death of osteoblasts. ${ }^{56}$

In contrast, administration of insulin to the point of hyperinsulinaemia stimulates osteoblast activity and mineral apposition rates. ${ }^{57}$ Treatment administered can also imply the differences that exist in disease severity further confounding the outcome of such studies.

Thus, the impact of endogenous insulin production, insulin sensitivity, and exogenous insulin administration as an anabolic agent for bone in T2DM has not been clarified.

\section{Fracture risk}

Both T1DM and T2DM are associated with increased fracture risk in spite of differences in the BMD.$^{58}$ Age-adjusted relative risk ratios (RR) for fracture among individuals with ranged from 1.4 to 2.9 and frequently demonstrated an increasing $\mathrm{RR}$ with longer duration of disease.

This would suggest that factors independent of BMD might also contribute to the increased RR for fractures. Falls and traumatic injuries that are associated with various other factors in the patients with DM can account for increased incidence of fractures in them. Specifically, hypoglycaemia unawareness and hypoglycemic seizures, visual impairment, peripheral neuropathy, and nocturnal polyuria are some of the important factors that can contribute to a higher risk of fall. ${ }^{59-61}$ Prolonged fracture union time and prolonged healing are also seen in patients with T2DM. ${ }^{62}$ Specifically, the presence of DM is associated with an increased risk of wound complications following surgical treatment of fractures and non-union or malunion of healing fracture sites.

\section{Oral hypoglycaemic agents and osteoporosis}

Effects of drugs used for DM should be considered along with the effect of DM on bone mineral metabolism. ${ }^{63-73}$ The effect of thiozolidinediones (TZD) observed in various clinical studies ${ }^{66-68}$ is given in the Table 2.The prevalence of osteoporosis in patients with T2DM in various studies is given in Table $3{ }^{69-73}$ TZD group of agents have been 


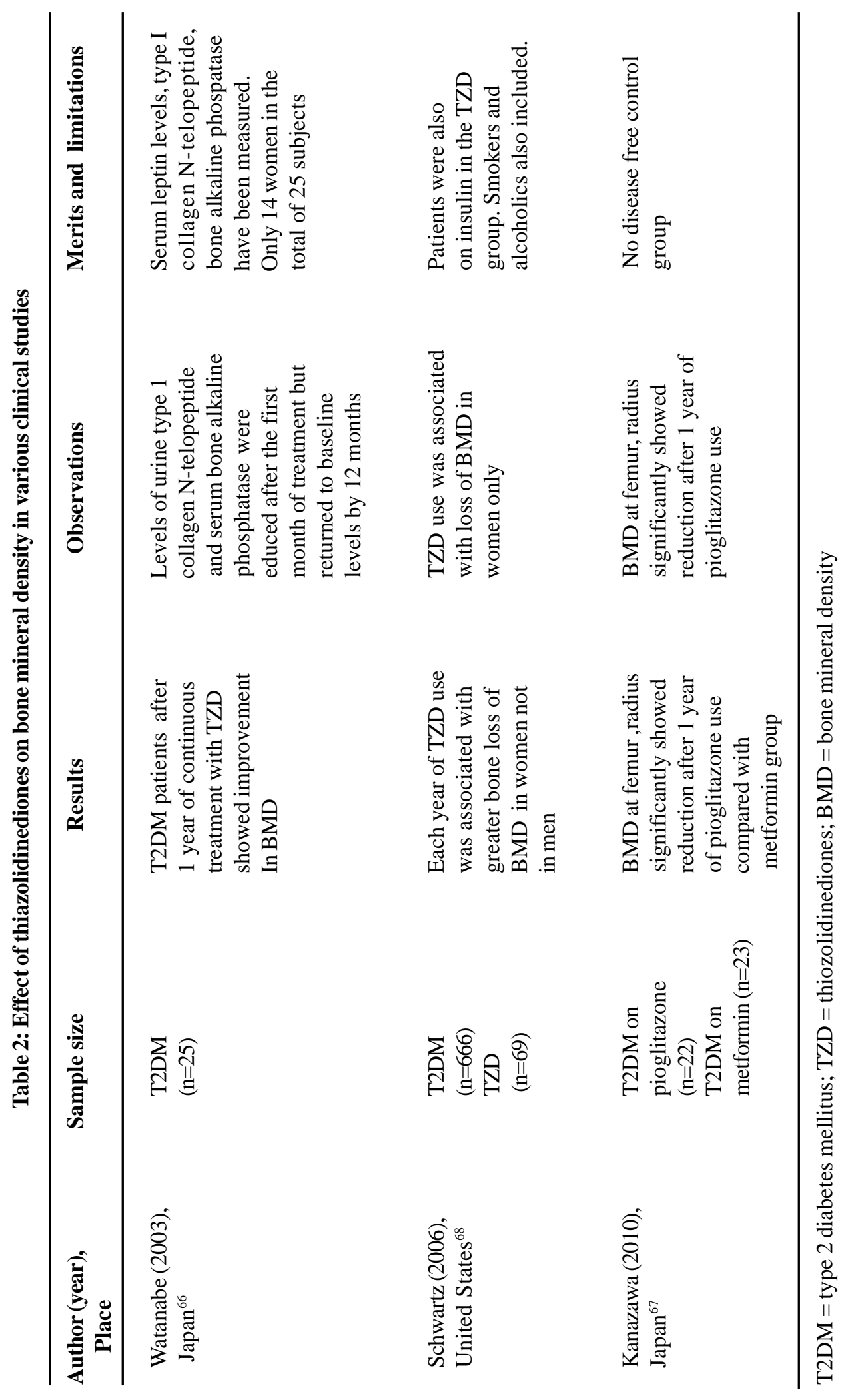




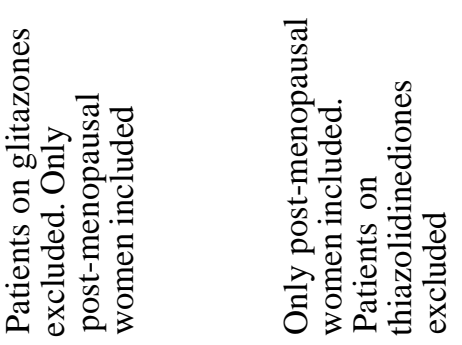

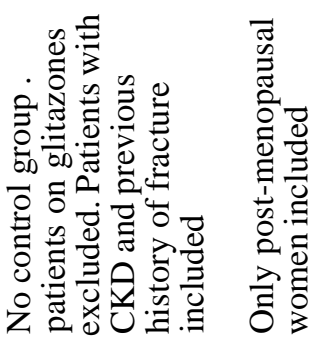

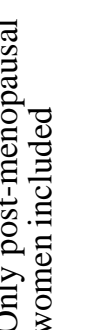

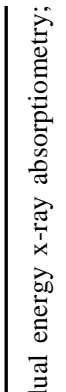

音 $\frac{\overrightarrow{0}}{0}$

完范

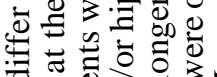

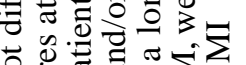

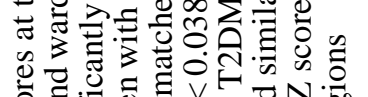

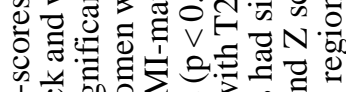

ठํ.

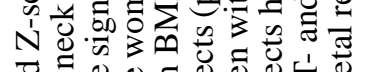

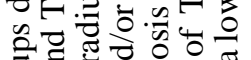

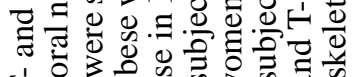

ธํำ

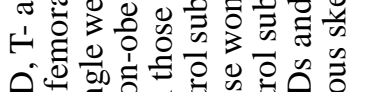

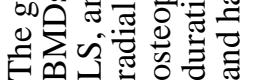

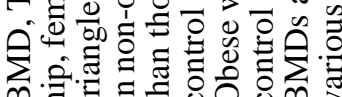

-

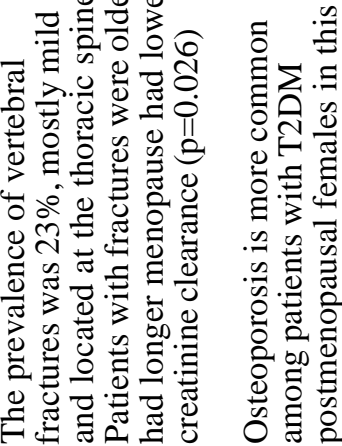

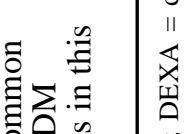

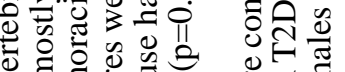

氖焉 寻

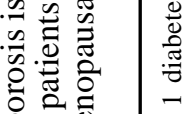

过

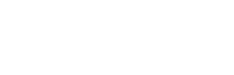

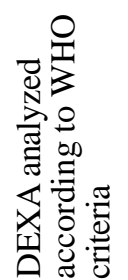

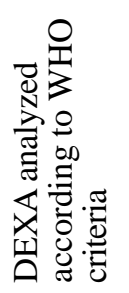

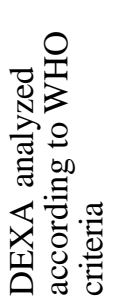

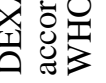

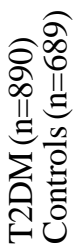

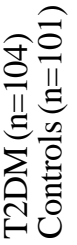

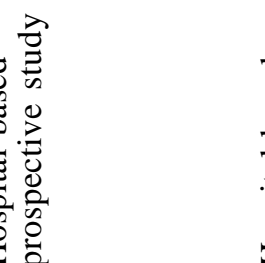

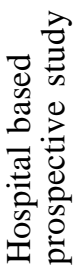

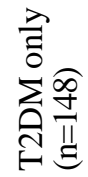

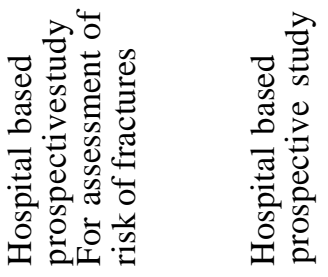

这

节

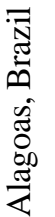

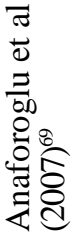

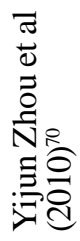

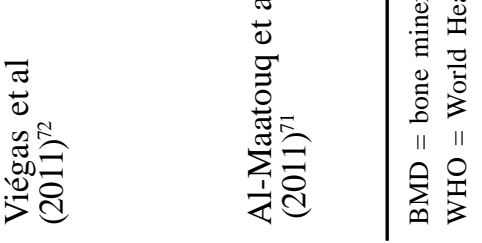


implicated in causing osteoporosis in various animal studies and some human studies available till date. ${ }^{78-80}$ One study has shown that these agents through their action on leptin metabolism have improved BMD ${ }^{81}$ Biguanides and sulphonylureas do not appear to have adverse effects on bone,Preclinical evidence suggests that incretinbased drugs may be beneficial for bone, but clinical evidence to support this hypothesis is not yet available. ${ }^{80}$

\section{Thiozolidinediones and bone metabolism}

Treatment with TZD class of antidiabetic drugs, causes bone loss and further increases fracture risk. In vitro and in-vivo animal studies have demonstrated that TZD-mediated PPAR $\gamma$ activation increases bone resorption and reduces the formation of new bone. A shift in marrow cells from osteoblast lineage to adipocyte formation due to PPAR $\gamma$ activation can result in reduced bone formation. ${ }^{63}$ Ageing and oestrogen deficiency are sensitizing factors to bone loss as a result of TZD therapy. ${ }^{64}$

In the RECORD trial, ${ }^{65}$ the incidence of fractures was higher in the rosiglitazone group. Fractures occurred mainly in the upper and distal lower limbs and were more common in women than in men. However, the primary objective of this study was to observe the effect of rosiglitazone in cardiovascular outcomes in oral agent combination therapy for T2DM.

\section{Prevalence of osteoporosis in patients with T2DM}

The study population considered for these studies constitute of predominantly postmenopausal women.Studies from Turkey and China ${ }^{69,70}$ suggest that the prevalence of osteoporosis in patients with T2DM were comparable to the control subjects. In a study from Saudi Arabia ${ }^{71}$ the patients with T2DM were observed to have higher prevalence of osteoporosis when compared with the study subjects. Contrary to the popular belief that patients with T2DM may have lesser risk of developing osteoporosis these studies show that the risk of osteoporosis in T2DM is comparable to the general population.
Similar to the patients with T1DM, patients with T2DM, who were once thought to be protected from osteoporosis due to higher BMD and obesity, are also at a higher risk for developing osteoporosis. Use of oral hypoglycamic drugs (especially the TZD group) has been associated with risk of osteoporosis. Therapeutic interventions by increasing the bone density and decreasing the risk of falls are the key to prevent fractures. Further work toward understanding the particular bone response to diabetes is important for diseasespecific tailored prevention and therapeutic strategies. In the meanwhile care of patients with diabetes should include an assessment of bone health.

\section{REFERENCES}

1. International Diabetes Federation. The IDF Diabetes Atlas. Fifth Edition. International Diabetes Federation; 2011. Available at URL: http:// www.idf.org/diabetesatlas. Accessed on December 2,2011.

2. Lane NE. Epidemiology, etiology and diagnosis of osteoporosis. Am J Obstet Gynecol 2006;194 (2 Suppl):S3-11.

3. Johnell O, Kanis JA. An estimate of the worldwide prevalence, mortality and disability associated with hip fracture. Osteoporos Int 2004;15:897-902.

4. Atik OS, Gunal I, Korkusuz F. Burden of osteoporosis. Clin Orthop Relat Res 2006; 443:19-24.

5. The World Health Report 2003: Shaping the future. Geneva World Health Organization: 2003.p.181.

6. Hui SL, Slemenda CW, Johnston CC Jr. The contribution of bone loss to postmenopausal osteoporosis. Osteoporos Int 1990;1:30-4.

7. Saadi HF, Reed RL, Carter AO, Qazaq HS, Al-Suhaili AR. Bone density estimates and risk factors for osteoporosis in young women. East Mediterr Health J 2001;7:730-7.

8. Pollitzer WS, Anderson JJ. Ethnic and genetic differences in bone mass: a review with a hereditary vs. environmental perspective. Am J Clin Nutr1989; 50:1244-59.

9. Rizzoli R, Bonjour JP. Determinants of peak bone mass and mechanisms of bone loss. Osteoporos Int1999; 9 Suppl: S17-23.

10. Bonjour JP, Thientz G, Law F, Slosman D, Rizzoli R. Peak bone mass. Osteoporos Int 1994; 4 Suppl 1: S713.

11. Rigo J, De Curtis M, Nyamugabo K, Pieltain C, Santerre J. Premature bone. In: Bonjour JP, Tsang 
RC, editors. Nutrition and bone development. Nestle Nutrition Workshop Series. Philadelphia: LippincottRaven; 1999: 83-9.

12. Bonjour JP, Rizzoli R. Bone acquisition in adolescence. In: Marcus R, Feldman D, Kelsey J, editors. Osteoporosis. San Diego: Academic Press; 1996. p. 465-76.

13. Armamento-Villareal R, Villareal DT, Avioli LV, Civitelli R. Estrogen status and heredity are major determinants of premenopausal bone mass. J Clin Invest 1992;90:2464-71.

14. Dhuper S, Warren MP, Brooks J-Gunn, Fox R. Effects of hormonal status on bone density in adolescent girls. J Clin Endocrinol Metab 1990;71:1083-8.

15. Ruiz JC, Mandel C, Garabedian M. Influence of spontaneous calcium intake and physical exercise on the vertebral and femoral bone mineral density of children and adolescents. J Bone Miner Res1995;10: 675-82.

16. Halioua L, Anderson JJ. Lifetime calcium intake and physical activity habits: independent and combined effects on the radial bone of healthy premenopausal Caucasian women. Am J Clin Nutr 1989; 49:534-41.

17. Varenna M, Binelli L, Zucchi F, Ghiringhlli D, Gallazzi M, Sinigaglia L. Prevalence of osteoporosis by education level in a cohort of postmenopausal women. Osteoporos Int 1999; 9: 236-41.

18. Frost HM. Bone remodeling dynamics. Springfield: Charles C. Thomas Company; 1963.

19. Raisz LG.Pathogenesis of osteoporosis: concepts, conflicts, and prospects. J Clin Invest 2005; 115: 331825.

20. Melton LJ $3^{\text {rd }}$. Epidemiology worldwide. Endocrinol Metab Clin North Am 2003;32:1-13.

21. Ojo F, Al Snih S, Ray LA, Raji MA, Markides KS. History of fractures as predictor of subsequent hip and nonhip fractures among older Mexican Americans. J Natl Med Assoc 2007;99:412-8.

22. Berg KM, Kunins HV, Jackson JL, Nahvi S, Chaudhry A, Harris KA Jr, et al. Association between alcohol consumption and both osteoporotic fracture and bone density. Am J Med 2008;121:406-18.

23. Poole KE, Compston JE. Osteoporosis and its management. BMJ 2006;333:1251-6.

24. WHO Scientific Group on the Prevention and Management of Osteoporosis. Geneva: World Health Organization; 2003.

25. Nieves JW. Osteoporosis: the role of micronutrients. Am J Clin Nutr 2005;81:1232S-9S.
26. Ilich JZ, Kerstetter JE. Nutrition in bone health revisited: a story beyond calcium. J Am Coll Nutr 2000;19:715-37.

27. Shapses SA, Riedt CS. Bone, body weight, and weight reduction: what are the concerns? J Nutr; 2006;136:1453-6.

28. Black AJ, Topping J, Durham B, Farquharson RG, Fraser WD. A detailed assessment of alterations in bone turnover, calcium homeostasis, and bone density in normal pregnancy. J Bone Miner Res 2000;15:557-63.

29. Naylor KE, Iqbal P, Fledelius C, Fraser RB, Eastell R. The effect of pregnancy on bone density and bone turnover. J Bone Miner Res 2000;15:129-37.

30. Karlsson MK, Ahlborg HG, Karlsson C. Maternity and bone mineral density. Acta Orthop 2005;76:2-13.

31. Sowers M, Crutchfield M, Jannausch M, Updike S, Corton G. A prospective evaluation of bone mineral change in pregnancy. Obstet Gynecol 1991;77:8415.

32. Kaur M, Pearson D, Godber I, Lawson N, Baker P, Hosking D. Longitudinal changes in bone mineral density during normal pregnancy. Bone 2003;32:44954.

33. Holmberg-Marttila D, Leino A, Sievänen H. Bone turnover markers during lactation, postpartum amenorrhea and resumption of menses. Osteoporos Int 2003;14:103-9.

34. Sowers M, Corton G, Shapiro B, Jannausch ML, Crutchfield M, Smith ML, Randolph JF, Hollis B. Changes in bone density with lactation. JAMA 1993;269:3130-5.

35. Kolthoff N, Eiken P, Kristensen B, Nielsen SP. Bone mineral changes during pregnancy and lactation: a longitudinal cohort study. Clin Sci (Lond) 1998; 94:405-12.

36. Kalkwarf HJ, Specker BL, Bianchi DC, Ranz J, Ho M. The effect of calcium supplementation on bone density during lactation and after weaning. N Engl J Med 1997;337:523-8.

37. Sowers MF, Hollis BW, Shapiro B, Randolph J, Janney CA, Zhang D, etal. Elevated parathyroid hormonerelated peptide associated with lactation and bone density loss. JAMA 1996;276:549-54.

38. VanHouten JN, Dann P, Stewart AF, Watson CJ, Pollak M, Karaplis AC, et al. Mammary-specific deletion of parathyroid hormone-related protein preserves bone mass during lactation. J Clin Invest 2003;112:1429-36.

39. Woodrow JP, Sharpe CJ, Fudge NJ, Hoff AO, Gagel RF, Kovacs CS. Calcitonin plays a critical role in regulating skeletal mineral metabolism during lactation.Endocrinology 2006 ;147:4010-21. 
40. Wysolmerski JJ. Interactions between breast, bone, and brain regulate mineral and skeletal metabolism during lactation. Ann N Y Acad Sci 2010;1192:161-9.

41. Sowers M, Eyre D, Hollis BW, Randolph JF, Shapiro B, Jannausch ML, etal. Biochemical markers of bone turnover in lactating and nonlactating postpartum women. J Clin Endocrinol Metab 1995;80:2210-6.

42. Vajda EG, Bowman BM, Miller SC. Cancellous and cortical bone mechanical properties and tissue dynamics during pregnancy, lactation, and postlactation in the rat. Biol Reprod 2001;65:689-95.

43. Michaëlsson K, Baron JA, Farahmand BY, Ljunghall S. Influence of parity and lactation on hip fracture risk. Am J Epidemiol 2001;153:1166-72.

44. Cummings SR, Nevitt MC, Browner WS, Stone K, Fox KM, Ensrud KE, etal. Risk factors for hip fracture in white women. Study of Osteoporotic Fractures Research Group. N Engl J Med 1995;332:767-73.

45. International Osteoporosis Foundation. Secondary osteoporosis. Available at URL: http:// www.iofbonehealth.org/patients-public/more-topics/ secondary-osteoporosis.html. Accessed on November 30, 2011.

46. Kanis JA. Diagnosis of osteoporosis and assessment of fracture risk. Lancet 2002;359:1929-36.

47. A report of Surgeon general. Bone health and osteoporosis: Washington. : U.S. Dept. of Health and Human Services, Public Health Service, Office of the Surgeon General; 2004.

48. Leslie WD, Adler RA, El-Hajj Fuleihan G, Hodsman $\mathrm{AB}$, Kendler DL, McClung M, etal. International Society for Clinical Densitometry. Application of the 1994 WHO classification to populations other than postmenopausal Caucasian women: the 2005 ISCD Official Positions. J Clin Densitom 2006;9:22-30.

49. Leib ES, Lewiecki EM, Binkley N, Hamdy RC; International Society for Clinical Densitometry. Official positions of the International Society for Clinical Densitometry. J Clin Densitom 2004;7:1-6.

50. Strotmeyer ES, Cauley JA, Schwartz AV, Nevitt MC, Resnick HE, Zmuda JM et al.The Health ABC Study. Diabetes is associated independently of body composition with BMD and bone volume in older white and black men and women: The Health, Aging, and Body Composition Study. J Bone Miner Res 2004;19:1084-91

51. Parkinson IH, Fazzalari NL. Interrelationships between structural parameters of cancellous bone reveal accelerated structural change at low bone volume. J Bone Miner Res 2003;18:2200-5.

52. el Miedany YM, el Gaafary S, el Baddini MA. Osteoporosis in older adults with non-insulin dependent diabetes mellitus: is it sex related? Clin
Exp Rheumatol 1999;17:561-7.

53. Isaia GC, Ardissone P, Di Stefano M, Ferrari D, Martina V, Porta M et al.Bone metabolism in type 2 diabetes mellitus. Acta Diabetol 1999;36:35-8.

54. Krakauer JC, McKenna MJ, Buderer NF, Rao DS, Whitehouse FW, Parfitt AM. Bone loss and bone turnover in diabetes. Diabetes 1995;44:775-82.

55. Rzonca SO, Suva LJ, Gaddy D, Montague DC, LeckaCzernik B. Bone is a target for the antidiabetic compound rosiglitazone. Endocrinology 2004;145:401-6.

56. Soroceanu MA, Miao D, Bai XY, Su H, Goltzman D, Karaplis AC. Rosiglitazone impacts negatively on bone by promoting osteoblast/ osteocyte apoptosis. J Endocrinol 2004;183:203-16.

57. Verhaeghe J, Visser WJ, Einhorn TA, Bouillon R. Osteoporosis and diabetes: lessons from the diabetic BB rat. Horm Res 1990;34:245-8.

58. Piepkorn B, Kann P, Forst T, Andreas J, Pfutzner J. Bone mineral density and bone metabolism in diabetes mellitus. Horm Metab Res 1997;29:584-91.

59. Reyes-Ortiz CA, Al Snih S, Loera J, Ray LA, Markides K. Risk factors for falling in older Mexican Americans. Ethn Dis 2004;14:417-22.

60. Schwartz AV, Hillier TA, Sellmeyer DE, Resnick HE, Gregg E, Ensrud KE, et al. Older women with diabetes have a higher risk of falls: a prospective study. Diabetes Care 2002;25:1749-54

61. Rix M, Andreassen H, Eskildsen P. Impact of peripheral neuropathy on bone density in patients with type 1 diabetes. Diabetes Care 1999;22:827-31

62. Loder RT. The influence of diabetes mellitus on the healing of closed fractures. Clin Orthop 1988;232:2106.

63. SchwartzAV, Sellmeyer DE, VittinghoffE, Palermo L, Lecka-Czernik B, Feingold KR. Thiazolidinedione (TZD) Use and Bone Loss in Older Diabetic Adults. J Clin Endocrinol Metab 2006;91:3349-54.

64. Lecka-Czernik B. Bone as a target of type 2 diabetes treatment. Curr Opin Investig Drugs 2009;10:108590.

65. Home PD, Pocock SJ, Beck-Nielsen H, Curtis PS, Gomis R, Hanefeld M. RECORD Study Team. Rosiglitazone evaluated for cardiovascular outcomes in oral agent combination therapy for type 2 diabetes (RECORD): a multicentre, randomised, open-label trial. Lancet 2009:20;373:2125-35.

66. Watanabe S, Takeuchi Y, Fukumoto S, Fujita H, Nakano T, Fujita T..Decrease in serum leptin by troglitazone is associated with preventing bone loss in type 2 diabetic patients. J Bone Miner Metab 2003;21:166-71. 
67. Kanazawa I, Yamaguchi T, Yano S, Yamamoto M, Yamauchi M, Kurioka S, etal. Baseline atherosclerosis parameter could assess the risk of bone loss during pioglitazone treatment in type 2 diabetes mellitus. Osteoporos Int 2010;21:2013-8.

68. Schwartz AV, Hillier TA, Sellmeyer DE, Resnick HE, Gregg E, Ensrud KE, et al. Older women with diabetes have a higher risk of falls: a prospective study. Diabetes Care 2002;25:1749-54.

69. Anaforoglu I, Nar-Demirer A, Bascil-Tutuncu N, Ertorer ME. Prevalence of osteoporosis and factors affecting bone mineral density among postmenopausal Turkish women with type 2 diabetes. J Diabetes Complicat 2009;23:12-7.

70. Zhou Y, Li Y, Zhang D, Wang J, Yang H. Prevalence and predictors of osteopenia and osteoporosis in postmenopausal Chinese women with type 2 diabetes. DiabetesRes Clin Pract 2010;90:261-9.

71. Al-Maatouq MA, El-Desouki MI, Othman SA, Mattar EH, Babay ZA, Addar M. Prevalence of osteoporosis among postmenopausal females with diabetes mellitus. Saudi Med J 2004;25:1423-7.

72. Viégas M, Costa C, Lopes A, Griz L, Medeiro A, Bandeira F. Prevalence of osteoporosis and vertebral fractures in postmenopausal women with type 2 diabetes mellitus and their relationship with duration of the disease and chronic complications. J Diabetes Complications 2011;25:216-21.

73. Chakrabarty N, Sarkar P, Pal SK, Banerjee R, Sarkar RN, Debnath NB. A study of bone mineral density in diabetes mellitus in eastern India. J Indian Med Assoc 2004;102:418-20. 